\title{
(อ) OPEN ACCESS \\ Should pregnant women be charged for non-invasive prenatal screening? Implications for reproductive autonomy and equal access
}

\author{
Eline M Bunnik, ${ }^{1}$ Adriana Kater-Kuipers, ${ }^{2}$ Robert-Jan H Galjaard, ${ }^{3}$ Inez D de Beaufort ${ }^{4}$
}

\begin{abstract}
${ }^{1}$ Medical Ethics and Philosophy of Medicine, Erasmus MC University Medical Center Rotterdam, Rotterdam, The Netherlands

${ }^{2}$ Medical Ethics and Philosophy of Medicine, Erasmus MC, University Medical Center Rotterdam, Rotterdam, The Netherlands

${ }^{3}$ Clinical Genetics, Erasmus MC, University Medical Center Rotterdam, Rotterdam, The Netherlands

${ }^{4}$ Medical Ethics and Philosophy of Medicine, Erasmus MC, University Medical Center Rotterdam, Rotterdam, The Netherlands
\end{abstract}

\section{Correspondence to}

Mrs Eline M Bunnik, Medica Ethics and Philosophy of Medicine, Erasmus MC, Rotterdam $3015 \mathrm{GE}_{\text {, }}$ Netherlands; e.bunnik@erasmusmc.nl

R-JHG and IDdB contributed equally.

Received 3 July 2019

Revised 2 September 2019 Accepted 9 September 2019

Published Online First 16 September 2019

\section{Check for updates}

(C) Author(s) (or their employer(s)) 2020. Re-use permitted under CC BY-NC. No commercial re-use. See rights and permissions. Published by BMJ.

\begin{tabular}{|l|}
\hline To cite: Bunnik EM, \\
Kater-Kuipers A, \\
Galjaard R-JH, et al. \\
J Med Ethics \\
2020;46:194-198. \\
\hline
\end{tabular}

\section{ABSTRACT}

The introduction of non-invasive prenatal testing (NIPT) in healthcare systems around the world offers an opportunity to reconsider funding policies for prenatal screening. In some countries with universal access healthcare systems, pregnant women and their partners are asked to (co)pay for NIPT. In this paper, we discuss two important rationales for charging women for NIPT: (1) to prevent increased uptake of NIPT and (2) to promote informed choice. First, given the aim of prenatal screening (reproductive autonomy), high or low uptake rates are not intrinsically desirable or undesirable. Using funding policies to negatively affect uptake, however, is at odds with the aim of screening. Furthermore, copayment disproportionally affects those of lower socioeconomic status, which conflicts with justice requirements and impedes equal access to prenatal screening. Second, we argue that although payment models may influence pregnant women's choice behaviours and perceptions of the relevance of NIPT, the copayment requirement does not necessarily lead to better-informed choices. On the contrary, external (ie, financial) influences on women's personal choices for or against prenatal screening should ideally be avoided. To improve informed decision-making, healthcare systems should instead invest in adequate non-directive, valuefocused pretest counselling. This paper concludes that requiring (substantial) copayments for NIPT in universal access healthcare systems fails to promote reproductive autonomy and is unfair.

\section{INTRODUCTION}

A new first-trimester prenatal screening test commonly referred to as non-invasive prenatal testing (NIPT) is in the process of being implemented in countries around the world. With NIPT, chromosomal abnormalities can be detected in cell-free DNA circulating in maternal blood, giving pregnant women the opportunity to consider reproductive options-either prepare for the birth of a child with a disability or terminate the pregnancy. In some countries, including the UK, France, Canada and the Netherlands, NIPT is available in implementation research settings. ${ }^{1}{ }^{2}$ In the USA, Israel and Australia, NIPT is available primarily through commercial providers. ${ }^{3}$ In other countries, such as Belgium, Denmark and Singapore, it is either already part of routine antenatal care ${ }^{4}$ or offered through publicly funded screening programmes. ${ }^{5}$ NIPT is procedurally safe and simple, and its test performance for trisomy 21 (Down syndrome), trisomy 18 (Edwards syndrome) and trisomy 13
(Patau syndrome) is better than that of the conventional combined test based on nuchal translucency ultrasound, blood tests and maternal age. Even in low-risk pregnancies, NIPT is characterised by high sensitivity and specificity. ${ }^{6}$ It requires only a blood draw from the pregnant woman at 9-11 weeks of gestation. NIPT is not a diagnostic test; as cell-free DNA is derived not from the fetus but from the placenta, an abnormal NIPT result requires confirmation through invasive follow-up diagnostic testing (ie, chorionic villus sampling or amniocentesis). Because of its better test performance for trisomies 21, 18 and 13, however, NIPT requires fewer invasive follow-up tests than does the combined test, and thus leads to fewer iatrogenic miscarriages.

First-trimester prenatal screening has traditionally been offered free of charge in many countries. A survey conducted in 2015 across 28 countries around the world shows that conventional firsttrimester screening was generally covered in full or in part by public health programmes, with the exception of Argentina, Ireland, India, the Netherlands, Mexico, Qatar and the USA. ${ }^{4}$ Funding policies for screening are likely to affect its uptake; in countries where first-trimester prenatal screening is fully publicly funded, the uptake is usually high, such as in Denmark (90\%) and Belgium (80\%), ${ }^{7}$ whereas in countries like the Netherlands, where women paid out of pocket for the combined test, the uptake has traditionally been lower, at around $30 \% .{ }^{8}$ In the US, NIPT costs approximately US $\$ 400,{ }^{9}$ and insurance coverage for NIPT is variable. ${ }^{3}$ In a recent study, US obstetricians indicated that the cost of NIPT is currently hampering its utilisation. ${ }^{10}$ Healthcare professionals in Canada, too, observe that financial cost is 'an important barrier' to accessing NIPT. ${ }^{11}$

The introduction of NIPT raises ethical quandaries. Notably, there are discussions with regard to the appropriate scope of NIPT. ${ }^{12-14}$ Dutch laboratories are licensed to screen for trisomies 13, 18 and 21 only, although pregnant women can choose to have incidental findings reported as well. These findings pertain mostly to other chromosomal abnormalities, which may be rarer, but can be equally or more severe, and of sufficiently understood clinical significance. In some countries, the scope of NIPT has expanded to include sex-chromosomal abnormalities and microdeletion syndromes. In this paper, when we write about NIPT, we consider the use of NIPT primarily as a first-tier ('universal') or second-tier ('contingent') screening test for trisomies 13, 18 and 21. The argument may be extended to other chromosomal 
abnormalities that are 'markedly severe', ${ }^{15}$ or 'serious congenital conditions and childhood disorders'. ${ }^{13}$ We do not consider the use of NIPT for the detection of other medical or non-medical conditions (including sex determination), for which there has thus far been less public support. ${ }^{16}$ Also, we proceed from the notion that prenatal screening programmes are acceptable, and that allowing women to terminate a pregnancy in case of a serious fetal health condition is acceptable.

The ongoing introduction of NIPT around the world requires a reconsideration of funding policies for first-trimester prenatal screening. Should pregnant women and their partners be charged for NIPT, and on what grounds? There are practical as well as principled reasons to charge women for NIPT. In resourceconstrained settings, societies may not have sufficient funds to offer NIPT free of charge. Universal NIPT is both more effective than the first-trimester combined test in detecting trisomies and more costly. ${ }^{17}$ In most 'cost-effectiveness' studies, however, the costs of the care and support required for children with chromosomal abnormalities are not taken into account. Furthermore, although the costs of NIPT may currently be among the main reasons for states to charge women, these costs will likely decrease in the future as the technology develops.

This paper, therefore, focuses on principled reasons for charging-assuming that the practical reasons for doing so (ie, lack of resources, organisational challenges) need not be decisive. We critically discuss two principled rationales for asking pregnant women and their partners to (co)pay for NIPT: to prevent increased uptake of screening and to improve informed decision-making. First, a financial contribution can function as a hurdle, making prenatal screening more difficult to obtain and discouraging women from taking part. Some of those who oppose widespread uptake of prenatal screening and/or abortion may not only wish to refrain from screening themselves, but may also prefer others to forgo screening. Asking a significant sum may help in maintaining or decreasing the number of women who participate in screening. A second moral justification for charging women is to promote informed and well-considered choices for or against the prenatal screening offer. Charging is believed to help women understand that first-trimester screening is not part of routine antenatal care, but something different. Copayment is believed to help create 'choice awareness' and to ensure well-considered participation in screening. Both rationales merit further scrutiny, as it is not self-evident that charging for NIPT is justifiable from a justice perspective or contributes to well-considered choices.

\section{Rationale 1: charging women to prevent increased uptake of screening}

One reason for charging pregnant women for NIPT is to prevent an increase in uptake of prenatal screening, and thus to prevent an increase in the number of abortions. Although commentators do not usually explicitly mention this rationale, it follows from the reverse concern that public funding of NIPT may encourage women to take part in prenatal screening. If the state offers prenatal screening free of charge, it gives the impression that it condones screening as a form of routine care among other antenatal care services. An offer of NIPT would lead to a higher uptake of screening and-following this rationale-a higher uptake is perceived to be problematic.

With the start of the Dutch NIPT implementation study in April 2017, for instance, it was feared that pregnant women would 'rush' to academic medical centres to obtain NIPT. ${ }^{18}$ The notion that all Dutch women would engage in screening was seen as intrinsically undesirable. Pregnant women and mothers of children with Down syndrome were concerned that abortion rates would rise, and that Down syndrome might disappear from society. ${ }^{19-21}$

This is not likely. In the Netherlands, the majority of women decline first-trimester screening altogether, even today, now NIPT is widely available. Moreover, not all prenatal screening results in abortion. In the period 2000-2013, around 85\% of pregnancies with a confirmed diagnosis of Down syndrome resulted in termination, ${ }^{22}$ which means that a substantial minority chose to continue the pregnancy. Certain groups in Dutch society hold a relatively high acceptance and positive image of Down syndrome; some Dutch women do not consider Down syndrome 'severe enough to justify termination of pregnancy'. ${ }^{23}$ The number is consistent with termination rates found in other countries, such as the USA, ${ }^{24}$ the $\mathrm{UK}^{25}$ and other European countries, ${ }^{26}$ but lower than the rates reported elsewhere, such as $93 \%$ in Australia ${ }^{27}$ and $98 \%$ in Denmark. ${ }^{28}$ Overall, the prevalence of Down syndrome has been relatively stable around the world since the early 1990 s. $^{29}$ This is not likely to change with the introduction of NIPT, as in countries like the UK and the Netherlands some women continue to opt for first-trimester prenatal screening 'for information only' and refrain from abortion. A recent review of studies from the USA, Asia and Europe suggested that termination rates following the introduction of NIPT were unchanged or even decreased. ${ }^{30}$

Even if Down syndrome would disappear from society, this may be considered a loss in terms of social diversity, but it may not be a soluble problem or a moral wrong as long as terminations resulted from pregnant women's autonomous decisions. A related-and possibly valid-concern is that if fewer children are born with Down syndrome, the acceptation of persons with Down syndrome and the quality of their medical care and support might decrease, ${ }^{20} 21$ and discrimination and stigmatisation of affected persons and families might increase. Pregnant women and their partners may indeed feel less free to carry an affected pregnancy to term if good-quality medical care and support were not available for disabled children. Reproductive autonomy, the stated aim of first-trimester prenatal screening, ${ }^{12}$ presupposes that disabled children receive the support they need. Therefore, the existence of 'decent, fair, inclusive and supportive policies with regard to the abilities and conditions of all people ${ }^{15}$ is a precondition for a responsible prenatal screening programme.

Charging money can be thought of as a political compromise to those who oppose widespread use of prenatal screening and/or abortion and believe that first-trimester screening may (need to) be available to women who actively and purposively request it, but should not be too readily available. (Co)payment thus serves as a barrier to access, aimed at discouraging women from taking part. However, this is not consistent with the aim of prenatal screening. Women should not be withheld from screening, just as those who oppose screening should not be put under pressure to take part. In Dutch counselling practices, women are presented with an 'information offer' about screening first, which they are free to refuse, to safeguard their 'right not to know'. Also, the ethical requirement of non-directiveness in counselling is meant to safeguard the voluntariness of participation. Such measures should be in place in screening programmes around the world to avoid any pressure on women to participate in screening just because it is 'the norm'. 31

In countries where screening and/or abortion are morally controversial, so it is argued, it is not obvious that society should bear the costs of prenatal screening. ${ }^{32}$ Other healthcare priorities may be more important than sustaining screening programmes aimed at promoting reproductive 'liberty and autonomy'. ${ }^{15}$ In 
response, we would like to stress that prenatal screening does not aim at promoting unrestricted reproductive liberty and autonomy, but at offering information about severe health conditions in the fetus that could be a reason for pregnant women to consider terminating the pregnancy, so as to prevent the birth of an affected child. Children born with trisomy 13 or 18 are severely ill, and most children die before birth or within days, weeks or months after birth. There is less consensus on Down syndrome as a justified reason to terminate an affected pregnancy; some children born with trisomy 21 may lead relatively contented lives, while others develop severe cognitive delays and somatic conditions. A life with Down syndrome, 'even if it does not involve major medical problems, is fraught with intellectual disabilities and [...] it is, in most cases, a life that is shorter than other human lives, ${ }^{33}$ Some prospective parents may wish to prevent this in their families. Empirically, there is broad societal support for public funding of NIPT for trisomies. A Canadian study found that the majority of women (66.9\%) thought that all pregnant women should have access to NIPT free of charge. ${ }^{11}$ Also women in Australia (93\% of respondents) have been found to support public funding of NIPT. ${ }^{34}$

Finally, by putting up a barrier that is higher for less affluent women than for more affluent women, the (co)payment requirement raises intractable justice concerns and hinders equity of access to first-trimester prenatal screening. Charging for NIPT affects disproportionally those who are least well off financially, which challenges the principle of equal access to first-trimester prenatal screening. The (co)payment requirement may in part explain the especially low uptake among groups of lower socioeconomic status and minority ethnic groups vis-à-vis groups of higher socioeconomic status, which has been found to be unrelated to attitudes towards screening. ${ }^{35}$ Rather, socioeconomically disadvantaged women are less likely to act on their (positive) attitudes towards screening than socioeconomically advantaged women when confronted with financial and physical barriers, such as requiring extra visits to the midwifery clinic. Women from minority ethnic groups may also be less knowledgeable about Down syndrome ${ }^{36}$ and other chromosomal abnormalities. Putting up a financial barrier may exacerbate these differences in uptake, ${ }^{37}$ and therewith it may exacerbate choice disparities among groups of higher and lower socioeconomic status. Offering NIPT free of charge is likely to reduce these disparities.

Alternatively, differentiated funding policies could be considered, in which women who can afford (co)paying for NIPT would be asked to do so, while those who cannot would be offered NIPT free of charge, or would be partly reimbursed afterwards. Although other ways to promote equal access to prenatal screening can thus be imagined, practical and logistical issues are likely to limit the feasibility of, for instance, differentiated pricing schemes.

Finally, in countries such as the Netherlands, where all pregnant women are offered a free ultrasound scan for structural anomalies at 20 weeks of gestation, charging for NIPT seems strikingly inconsistent. Despite morally relevant differences between the two screening tests (notably, although the 20 -week ultrasound is aimed primarily at reproductive autonomy, it also aims to improve maternal health and pregnancy outcomes), we find it remarkable that NIPT tends to elicit ethical discussions, whereas the 20 -week ultrasound does not.

In sum, funding policies should support prenatal screening programmes in achieving their aim of promoting reproductive autonomy. They should not be used to negatively affect uptake rates.
Rationale 2: charging women to improve informed decisionmaking

A second argument brought forward in public discussions for charging money for NIPT is that it will improve decisionmaking. ${ }^{38}$ A financial contribution to NIPT is thought to have the benefit of signalling to pregnant women and their partners that screening is optional: screening is an offer that may have far-reaching implications that should be considered beforehand. ${ }^{39}$ Because NIPT requires only a simple blood draw, just like other routine screening tests offered during the pregnancy, such as tests for HIV, hepatitis B, syphilis, blood type, Rhesus factor or antibodies, observers are concerned that women will thoughtlessly accept NIPT. ${ }^{12}$ Also, they may feel less justified in forsaking screening, as NIPT 'removes the risk to pregnancy as a reason for declining testing, ${ }^{40}$ and may experience societal pressure to take part in screening. Meeting the aim of reproductive autonomy is generally considered to require 'informed choice' for or against a screening offer. Participation in screening should be the result of such adequately informed, voluntary and valueconsistent decisions, ${ }^{41}$ not of passive acceptance or acquiescence to societal pressure.

It is feared that because of the non-invasive character of NIPT, health professionals may treat the informed choice process differently-less stringently-than they would in the context of invasive testing, requiring less time to consider or not asking for written informed consent. ${ }^{42}$ NIPT would be presented by counsellors as a routine procedure and would consequently be perceived as such by pregnant women and their partners, a concern referred to as 'routinisation'. ${ }^{43}$ If women may not appreciate the significance of the test, it would 'become more difficult to achieve the aim of enabling autonomous reproductive choices'. ${ }^{12}$ In sum, in the absence of accepted reasons not to take part in first-trimester prenatal screening, such as safety or financial considerations, pregnant women may consider less thoroughly whether or not to take part. Also, state funding is believed to send a 'legitimizing' message about the importance of NIPT, implying that the government encourages screening, ${ }^{38}$ making pregnant women more likely to participate without deliberation.

Putting up a (small) barrier by charging women, on the other hand, so it is argued, may help reinstall well-considered decision-making. ${ }^{39}$ If women must pay $€ 175$, the fee required in the Netherlands, or the small sum of $€ 8.68$, the fee required in Belgium, for NIPT, they will deliberate the benefits, risks and implications of screening. Especially in countries like the Netherlands, where all 'medically necessary' healthcare services are offered free of charge, including the 20-week ultrasound scan, the copayment requirement may signal to women that NIPT is a different test, and help them understand that NIPT 'is an offer that can be declined'. ${ }^{44}$ At the same time, however, it may signal that first-trimester screening is less relevant and lead women to (mistakenly) believe that screening is 'not necessary ${ }^{23}$ because of an assumed low risk of fetal abnormalities.

Thus, reimbursement policies are not neutral and may influence women's choice behaviours. But is charging a substantial or a 'symbolic' sum an effective way to promote informed choices? Does it not have adverse moral implications? Are there no subsidiary and better ways to prompt women to make informed choices?

Although many women are willing to copay for NIPT, ${ }^{45}$ for some women, the costs of first-trimester screening withhold them from taking part. ${ }^{23} 46$ Personally incurred costs significantly influence pregnant women's choices whether or not to undergo 
screening. ${ }^{47} 48$ For a majority of Canadian women (66.4\%), costs have 'a lot of impact' (5 on the 1-5 scale) on their decision to use screening. ${ }^{11}$ When a prenatal screening offer is declined on the basis of financial constraints, in fact quite the opposite from the ideal of informed choice is being realised: women are not choosing for or against NIPT based on their values, but because of financial constraints.

To illustrate the caveat, imagine that an opposite policy would be proposed: women who do not take part in prenatal screening are asked to pay a fee of $€ 175$. Policy makers would claim that this fee was introduced to prompt women to more thoroughly consider their decision. The fee, however, will likely be perceived by pregnant women as a discouragement or a punishment for the decision not to take part. This policy would signal that participation in screening is the preferred option and may limit women's freedom to decline screening, thus failing to promote informed choice. Strictly speaking, if a fee is considered instrumental in promoting informed choice, it should apply to both options (screening and not screening). For if reproductive autonomy is the justified aim of prenatal screening programme, both options should be considered equally valuable and equally acceptable. A fee should be asked for both options or none.

In sum, it is unclear how funding policies best serve reproductive autonomy. We have seen that there is no reason to assume that either a financial barrier or a fully reimbursed test will promote informed choice. To help women make choices regarding screening that are well informed, voluntary and consistent with their values, other solutions must be sought.

To make informed choices, women need time to become informed about screening, to talk to healthcare professionals and others, to imagine futures with children with disabilities, and to deliberate their options. Repeat discussions with healthcare professionals, over time, may be preferable to 'only one point of contact'. ${ }^{3}$ Another requirement may be good information about the implications of screening, offered individually and/or collectively, and through multiple modalities, including written information material and audiovisual material, and-if requested-balanced narratives from parents of children with disabilities to illustrate the range of experiences of living with and caring for children with disabilities. ${ }^{49}$ Further, women may need to be assisted in explicating their values and in making decisions in accordance with these values. In the Netherlands, obstetricians and midwives are specifically trained to focus on deliberation in pretest counselling. Counsellors are expected to conduct $30 \mathrm{~min}$ dedicated face-to-face discussions with pregnant women to facilitate informed choice for or against the NIPT offer. $^{50}$

To help increase choice awareness regarding first-trimester prenatal screening, pretest counselling may therefore need to focus on conveying key information about the aim and utility of prenatal screening, and foremost on the question whether women and their partners wish to start on the trajectory of reproductive decision-making (at all). The decision (not) to take part in screening should be based on women's values, not on their financial resources-although pregnant couples may reasonably ask themselves whether they have the social, practical and financial means to care for a child with a disability. Health professionals should discuss with pregnant women and their partners the reasons why they would wish to use screening, and what they would do in case of abnormalities. ${ }^{50}$ Not making people pay, but offering adequate pretest counselling should thus be (part of) a solution to safeguard informed choice. The offering of value-based pretest counselling will likely be more effective in promoting reproductive autonomy than the asking of a copayment for NIPT.

\section{CONCLUSION}

We have argued that the (co)payment requirement for NIPT is not a necessary nor a subsidiary approach to the promotion of informed choice among pregnant women and their partners, and does not serve reproductive autonomy. While informed choice remains of paramount importance in all prenatal screening programmes, there are no indications that charging women for NIPT will prove effective in accomplishing this. In fact, it may lead to the opposite of reproductive autonomy, when women forgo screening not based on well-considered choice, but simply because of financial constraints. Although reimbursement policies will likely affect pregnant women's and their partners' choice behaviour, neither full reimbursement nor the asking of a copayment is fully neutral, and neither will in and of itself improve informed choice. Rather, informed choice should be accomplished through adequate information provision and value-based pretest counselling focused on the promotion of choice awareness and deliberation.

Funding policies should not be used to prevent increased uptake of first-trimester prenatal screening. Financial barriers will disproportionately affect those of lower socioeconomic status, which is not in line with general justice requirements nor with the aim of prenatal screening. Instead, full reimbursement of NIPT for trisomies 13, 18 and 21-and in future, possibly for other serious childhood disorders-will help to guarantee equal access to prenatal screening and reproductive options.

Contributors EMB drafted the manuscript. AK-K, R-JHG and IdB offered substantial contributions to the conception of the work and critically revised it for important intellectual content. All authors have approved the final version of the manuscript.

Funding This study is a result of a research project 'Towards an ethically robust scope of NIPT', which was funded by ZonMw, dossier number 70-73000-98-116.

Competing interests None declared.

Patient consent for publication Not required.

Provenance and peer review Not commissioned; externally peer reviewed.

Open access This is an open access article distributed in accordance with the Creative Commons Attribution Non Commercial (CC BY-NC 4.0) license, which permits others to distribute, remix, adapt, build upon this work non-commercially, and license their derivative works on different terms, provided the original work is properly cited, appropriate credit is given, any changes made indicated, and the use is non-commercial. See: http://creativecommons.org/licenses/by-nc/4.0/.

\section{REFERENCES}

1 Chitty LS, Wright D, Hill M, et al. Uptake, outcomes, and costs of implementing noninvasive prenatal testing for Down's syndrome into NHS maternity care: prospective cohort study in eight diverse maternity units. BMJ 2016;354:i3426.

2 Oepkes D, Page-Christiaens GCL, Bax CJ, et al. Trial by Dutch laboratories for evaluation of non-invasive prenatal testing. Part I-clinical impact. Prenat Diagn 2016;36(12):1083-90.

3 Allyse M, Minear MA, Berson E, Rote M, et al. Non-Invasive prenatal testing: a review of international implementation and challenges. Int J Womens Health 2015;7:113-26.

4 Minear MA, Lewis C, Pradhan S, et al. Global perspectives on clinical adoption of NIPT. Prenat Diagn 2015;35(10):959-67.

5 Beel V. Regering maakt downtest (bijna) gratis voor iedereen, 2017. De Standaard 29 May. Available: http://www.standaard.be/cnt/dmf20170528_02901527 [Accessed 31 May 2019]. [in Dutch].

6 Hartwig TS, Ambye L, Werge L, et al. Non-Invasive Prenatal Testing (NIPT) in pregnancies with trisomy 21,18 and 13 performed in a public setting - factors of importance for correct interpretation of results. Eur J Obstet Gynecol Reprod Biol 2018;226:35-9.

7 Neyt M, Hulstaert F, Gyselaers W. Introducing the non-invasive prenatal test for trisomy 21 in Belgium: a cost-consequences analysis. BMJ Open 2014;4(11):e005922. 
8 Crombag NM, Bensing JM, ledema-Kuiper $R$, et al. Determinants affecting pregnant women's utilization of prenatal screening for Down syndrome: a review of the literature. J Matern Fetal Neonatal Med 2013;26(17):1676-81.

9 Abbott Pathology. Does Medicare cover the cost of Generation(R) prenatal test? Available: http://www.abbottpathology.com.au/lamaPatient/MyTesting/NoninvasiveP renatalTesting(NIPT).aspx [Accessed 31 May 2019].

10 Brewer J, Demers L, Musci T. Survey of US obstetrician opinions regarding NIPT use in general practice: implementation and barriers. J Matern Fetal Neonatal Med 2017;30(15):1793-6.

11 Birko S, Ravitsky V, Dupras C, et al. The value of non-invasive prenatal testing: preferences of Canadian pregnant women, their partners, and health professionals regarding NIPT use and access. BMC Pregnancy Childbirth 2019;19(1):22.

12 Dondorp W, de Wert G, Bombard Y, et al. Non-invasive prenatal testing for aneuploidy and beyond: challenges of responsible innovation in prenatal screening. Eur J Hum Genet 2015:23(11):1438-50.

13 Stapleton G. Qualifying choice: ethical reflection on the scope of prenatal screening. Med Health Care Philos 2017;20(2):195-205.

14 Kater-Kuipers A, Bunnik EM, de Beaufort ID, et al. Limits to the scope of non-invasive prenatal testing (NIPT): an analysis of the International ethical framework for prenatal screening and an interview study with Dutch professionals. BMC Pregnancy Childbirth 2018;18(1):409.

15 Munthe C. A new ethical landscape of prenatal testing: Individualizing choice to serve autonomy and promote public health: a radical proposal. Bioethics 2015;29(1):36-45

16 Bowman-Smart H, Savulescu J, Mand C, et al. 'Is it better not to know certain things?': views of women who have undergone non-invasive prenatal testing on its possible future applications. J Med Ethics 2019;45(4):231-8.

17 García-Pérez L, Linertová R, Álvarez-de-la-Rosa M, et al. Cost-Effectiveness of cell-free DNA in maternal blood testing for prenatal detection of trisomy 21, 18 and 13: a systematic review. Eur J Health Econ 2018;19(7):979-91.

18 Huisman C. Zwangere vrouwen hebben weinig interesse in gesubsidieerde NIPT-test, 2017Volkskrant 22 September. Available: https://www.volkskrant.nl/gs-bce5f06e [Accessed 31 May 2019 [in Dutch].

19 van Schendel RV, Kleinveld JH, Dondorp WJ, et al. Attitudes of pregnant women and male partners towards non-invasive prenatal testing and widening the scope of prenatal screening. Eur J Hum Genet 2014;22(12):1345-50.

20 Lewis C, Silcock C, Chitty LS. Non-Invasive prenatal testing for Down's syndrome: pregnant women's views and likely uptake. Public Health Genomics 2013; 16(5):223-32.

21 van Schendel RV, Kater-Kuipers A, van Vliet-Lachotzki EH, et al. What do parents of children with Down syndrome think about non-invasive prenatal testing (NIPT)? J Genet Couns 2017:26(3):522-31.

22 de Groot-van der Mooren MD, Tamminga S, Oepkes D, et al. Older mothers and increased impact of prenatal screening: stable livebirth prevalence of trisomy 21 in the Netherlands for the period 2000-2013. Eur J Hum Genet 2018;26(2):157-65.

23 Crombag NMTH, Boeije H, ledema-Kuiper R, et al. Reasons for accepting or declining Down syndrome screening in Dutch prospective mothers within the context of national policy and healthcare system characteristics: a qualitative study. BMC Pregnancy Childbirth 2016;16(1):121.

24 Natoli JL, Ackerman DL, McDermott S, et al. Prenatal diagnosis of Down syndrome: a systematic review of termination rates (1995-2011). Prenat Diagn 2012;32(2):142-53.

25 Gil MM, Revello R, Poon LC, et al. Clinical implementation of routine screening for fetal trisomies in the UKNHS: cell-free DNA test contingent on results from firsttrimester combined test. Ultrasound Obstet Gynecol 2016:47(1):45-52.

26 Boyd PA, DeVigan C, Khoshnood B, et al. Survey of prenatal screening policies in Europe for structural malformations and chromosome anomalies, and their impact on detection and termination rates for neural tube defects and Down's syndrome. BJOG: Int J O \& G 2008:115(6):689-96.

27 Maxwell S, Bower C, O'Leary P. Impact of prenatal screening and diagnostic testing on trends in Down syndrome births and terminations in Western Australia 1980 to 2013. Prenat Diagn 2015;35(13):1324-30.
28 Crombag NMTH, Vellinga YE, Kluijfhout SA, et al. Explaining variation in Down's syndrome screening uptake: comparing the Netherlands with England and Denmark using documentary analysis and expert stakeholder interviews. BMC Health Serv Res 2014; 14(1).

29 Loane M, Morris JK, Addor M-C, et al. Twenty-Year trends in the prevalence of Down syndrome and other trisomies in Europe: impact of maternal age and prenatal screening. Eur J Hum Genet 2013:21(1):27-33.

30 Hill M, Barrett A, Choolani M, et al. Has noninvasive prenatal testing impacted termination of pregnancy and live birth rates of infants with Down syndrome? Prenat Diagn 2017;37(13):1281-90.

31 Gottfredsdóttir H, Björnsdóttir K, Sandall J. How do prospective parents who decline prenatal screening account for their decision? A qualitative study. Soc Sci Med 2009;69(2):274-7.

32 Munthe C. Permissibility or priority? testing or screening? essential distinctions in the ethics of prenatal testing. Am J Bioeth 2017:17(1):30-2

33 Svenaeus F. Phenomenology of pregnancy and the ethics of abortion. Med Health Care Philos 2018;21(1):77-87.

34 Bowman-Smart H, Savulescu J, Mand C, et al. 'Small cost to pay for peace of mind': Women's experiences with non-invasive prenatal testing. Aust N Z J Obstet Gynaecol:46.

35 Posthumus AG, Peters $\mid \mathrm{A}$, Borsboom GJ, et al. Inequalities in uptake of prenatal screening according to ethnicity and socio-economic status in the four largest cities of the Netherlands (2011-2013). Prenat Diagn 2017;37(10):959-67.

36 Chilaka VN, Konje JC, Stewart CR, et al. Knowledge of Down syndrome in pregnant women from different ethnic groups. Prenat Diagn 2001;21(3):159-64.

37 Health Council of the Netherlands (Gezondheidsraad). Prenatale screening. The Hague: health Council of the Netherlands 2016. [in Dutch].

38 Vanstone M, Cernat A, Majid U, et al. Perspectives of pregnant people and clinicians on noninvasive prenatal testing: a systematic review and qualitative meta-synthesis. Ont Health Technol Assess Ser 2019;19(5):1-38.

39 Van Schendel R, Lachmeijer A, Dondorp W, et al. Verantwoorde introductie van NIPT: Huidige en toekomstige scenario's Verslag van een stakeholdermeeting ESPRIT studie. ESPRIT 2014. [in Dutch].

40 Newson AJ. Ethical aspects arising from non-invasive fetal diagnosis. Semin Fetal Neonatal Med 2008;13(2):103-8.

41 Marteau TM, Dormandy E, Michie S. A measure of informed choice. Health Expect 2001:4(2):99-108.

42 Silcock C, Liao L-M, Hill M, et al. Will the introduction of non-invasive prenatal testing for Down's syndrome undermine informed choice? Health Expect 2015;18(5):1658-71.

43 Kater-Kuipers A, de Beaufort ID, Galjaard R-JH, et al. Ethics of routine: a critical analysis of the concept of 'routinisation' in prenatal screening. J Med Ethics 2018;44(9):626-31.

44 Swedish Council on Medical Ethics. Summary of a report: Analysis of fetal DNA in the woman's blood: Non-invasive prenatal testing (NIPT) for trisomy 13, 18 and 21 ethical aspects. Swedish Council on Medical Ethics 2015.

45 van Schendel RV, Dondorp WJ, Timmermans DRM, et al. NIPT-based screening for Down syndrome and beyond: what do pregnant women think? Prenat Diagn 2015;35(6):598-604

46 Bakker M, Birnie E, Pajkrt E, et al. Low uptake of the combined test in The Netherlands--which factors contribute? Prenat Diagn 2012;32(13):1305-12.

47 Verweij EJ, Veersema D, Pajkrt E, et al. Decision making in prenatal screening: money matters. Acta Obstet Gyneco/ Scand 2015:94(2):212-4.

48 Garrouste C, Le J, Maurin E. The choice of detecting Down syndrome: does money matter? Health Econ 2011;20(9):1073-89.

49 Skjøth MM, Draborg E, Pedersen CD, et al. Providing information about prenatal screening for Down syndrome: a systematic review. Acta Obstet Gynecol Scand 2015;94(2):125-32.

50 Koninklijke Nederlandse Organisatie van Verloskundigen (KNOV). Niet-invasieve prenatale test (NIPT): counseling NIPT, eisen, 2018. Available: https://www.knov. nl/vakkennis-en-wetenschap/tekstpagina/504-3/niet-invasieve-prenatale-test-nipt/ hoofdstuk/1150/counseling-nipt-eisen/ [Accessed 31 May 2019 [in Dutch]. 